\title{
Appropriate Management of Attenuated Familial Adenomatous Polyposis: Report of a Case and Review of the Literature
}

\author{
Aleksandra Sokic-Milutinovic ${ }^{a, b}$

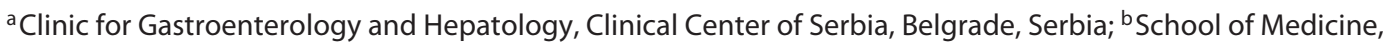 \\ University of Belgrade, Belgrade, Serbia
}

\section{Keywords}

Attenuated familial adenomatous polyposis · Screening ·

Extracolonic malignancies

\begin{abstract}
Hereditary polyposis syndromes in which APC gene germline mutations can lead to colorectal carcinogenesis are familial adenomatous polyposis (FAP), attenuated FAP (AFAP) and MUTYH-associated polyposis. All 3 syndromes increase the potential for the development of colorectal cancer. AFAP is diagnosed if less than 100 adenomas are detected in the colon at presentation. AFAP is inherited in an autosomal dominant manner. We present a case of a 22-year-old female with AFAP who was treated with endoscopic polypectomy and surveilled by annual colonoscopy. Guidelines for AFAP surveillance suggest annual colonoscopy with endoscopic polypectomy in asymptomatic individuals. Indications for immediate surgery include documented or suspected cancer or significant symptoms. Preferred surgical option in AFAP is colectomy and ileo-rectal anastomosis. Surveillance of the AFAP patients should include upper Gl endoscopy and duodenoscopy with random biopsies of fundic gland polyps and endoscopic resection of detected adenomas. Annual
\end{abstract}

๑) 2019 S. Karger AG, Basel

E-Mail karger@karger.com www.karger.com/ddi thyroid ultrasound is indicated due to increased risk for thyroid cancer. In pediatric patients tested positive for germline mutation of $A P C$ gene screening for hepatoblastoma using alpha-fetoprotein and liver ultrasound should be performed.

(c) 2019 S. Karger AG, Basel

\section{Introduction}

Three hereditary syndromes in which germline mutations can lead to colorectal carcinogenesis are familial adenomatous polyposis (FAP), attenuated FAP (AFAP), and MUTYH-associated polyposis (MAP). All 3 syndromes are manifested by the onset of multiple colorectal adenomas in early age with different but increased potential for the development of colorectal cancer (CRC) [1-3].

FAP is defined by the presence of more than 100 synchronous colorectal adenomas [1]. In FAP patients, the development of CRC is inevitable. The underlying genetic mechanism is germline mutation of the APC gene on chromosome $5 \mathrm{q} 21[4,5]$. FAP is inherited in an autosomal-dominant manner; however, up to one-third of newly diagnosed cases do not belong to previously identified FAP families [5-8]. 
On the other hand, AFAP syndrome is diagnosed if less than 100 adenomas are detected in the colon at presentation. AFAP is inherited in an autosomal-dominant pattern, but APC gene mutations differ from those detected in classic FAP patients $[2,3,9,10]$.

MAP was described in 2002; it is inherited in an autosomal-recessive pattern and represents an attenuated polyposis syndrome [11].

A variety of benign and malignant neoplasms in other organs may occur as a result of $A P C$ gene mutation in FAP patients. The most commonly affected are the thyroid, adrenal glands, small intestine, retina, bones and skin.

The purpose of this review is to highlight the differences in both the diagnostic and therapeutic approach to the patients with AFAP as opposed to FAP patients and also to review indications for genetic testing according to currently accepted guidelines.

\section{Report of a Case}

A 22-year-old female was referred to the Clinic of Gastroenterology and Hepatology Clinical center of Serbia for expert colonoscopy and decision on subsequent proctocolectomy, since polyps were seen during colonoscopy in the regional hospital. The patient was symptom-free. At the age of 20, first colonoscopy was performed due to positive family history for FAP and revealed multiple polyps. On admission, general physical examination was normal. All routine laboratory tests were within normal range. Patient's personal history was unremarkable; however, family history was positive for FAP syndrome, that is, the father died from metastatic CRC at the age of 45 and diagnosis of FAP was established. The father had no siblings. The mother was healthy. The patient has 2 siblings, an older sister and a younger brother. The patient's older sister had anemia and underwent proctocolectomy after FAP was diagnosed at the age of 20. The younger brother had blood in stool and anemia and proctocolectomy was performed at the age of 14 after colonoscopy revealed more than 100 adenomas. Neither the patient nor her siblings had children at the time the manuscript was written. In our patient, repeated colonoscopy revealed a total of 7 polyps that were endoscopically resected. The largest polyp was $8 \mathrm{~mm}$ in diameter. Histology revealed tubular adenomas with low-grade dypslasia and no high-grade dysplasia in any of the polyps. Screening for gastric and proximal small bowel tumors was performed using esophagogas- troduodenoscopy and polyps were not detected. Proctocolectomy was not indicated; annual endoscopic surveillance was recommended and is ongoing. Follow-up started in 2015 and annual control colonoscopies did not reveal new adenomas. Patient is still symptom-free. Genetic testing was advised, but due to technical difficulties it was not completed by the time this article was written. Written informed consent was obtained from the patient both for conducting diagnostic procedures and for data publication.

\section{Discussion}

In our patient, the diagnosis of AFAP was established since she had less than 100 adenomas at presentation. Based on the positive family history the patient's condition was inherited in an autosomal dominant pattern.

\section{Genetic Background of AFAP}

FAP and AFAP both arise from germline mutations of the APC gene on chromosome $5 \mathrm{q} 21[4,5] . A P C$ is a tumor-suppressor gene and its inactivation occurs only if the patient has both alleles damaged by mutation.

Classic FAP is dominantly inherited and the penetration of the mutation is almost $100 \%$. Two-thirds of patients belong to families with established FAP syndrome, while in approximately one-third of patients, de novo germline mutation or mosaicism is the underlying cause of FAP [6-8]. Adenomas occur after second previously normal allele is damaged, since FAP patients inherit one allele in a mutated form. Progression from adenoma to CRC occurs after the $A P C$ gene is inactivated if mutations accumulate in other genes like K-ras and p53. Carcinogenesis cascade shows a similar sequence of events as in sporadic CRC. Most mutations leading to APC gene inactivation occur in the $5^{\prime}$ end of exon 15 termed mutation cluster region [12]. The location of mutations in the APC gene determines the number of colonic adenoma and individuals with over one thousand adenomas were diagnosed with mutations of mid-portion of the APC gene [13].

In AFAP patients, $A P C$ gene mutations occur in 3 distinct locations: the far proximal $\left(5^{\prime}\right)$ end of the gene $(5$ first exons), the far distal ( $\left.3^{\prime}\right)$ end of the gene (after codon 1580), or in locations of exon $9[9,14]$. According to the available data, higher incidences of desmoid tumors have been associated with $3^{\prime}$ APC gene mutations, although 
extraintestinal malignancies overall in AFAP are not as frequent as in classic FAP [15].

In MAP, the underlying mechanism responsible for adenoma formation is a biallelic mutation in the MUTYH gene located at chromosome locus 1p34.3-p32.1. This particular gene is involved in the base excision repair pathway and MAP results from homozygous or compound heterozygous MUTYH gene mutations. Mutations in the MUTYH gene are responsible for the oxidative damage to DNA. In individuals of European ancestry with MAP, the majority harbor $2 \mathrm{MUTYH}$ gene missense mutations, namely, Y179C and G396D [1, 16].

\section{Genetic Testing in Adenomatous Polyposis Syndrome}

Prevalence of FAP is, according to the available data, 2.29-3.2 cases per 100,000 individuals. FAP affects both men and women equally [17-19], while the prevalence of AFAP is not established mainly because AFAP is a newer entity and these patients were previously misclassified as classic FAP. Overall, CRC in FAP and AFAP patients accounts for less than $1 \%$ of all CRC cases. Diagnosis of AFAP is based on genetic testing in patients belonging to the families with FAP or AFAP, or if clinical presentation is suggestive of adenomatous polyposis syndrome with or without extracolonic manifestations, the genetic testing described earlier should be undertaken.

Testing should be advised to patients whose phenotype of disease is suggestive for adenomatous polyposis syndrome with more than 10 cumulative adenomas and/or extraintestinal manifestations typical for FAP with no family history of adenomatous polyposis syndrome. Genetic analysis should also be undertaken in relatives of patients with known germline mutation, but in this case, testing is done for a particular germline mutation $[1,16,20]$.

Genetic testing in patients with suspected adenomatous polyposis syndrome includes APC and MUTYH gene mutation analysis.

Timely genetic testing in families with known adenomatous polyposis syndrome provides personalized follow-up and therapeutic strategies. The main obstacles preventing timely genetic testing in these patients were the costs and time required for the analysis of multiple genes using Sanger sequencing. The development of nextgeneration DNA-sequencing technologies is considered revolutionary technology that would enable wider use of genetic testing in adenomatous polyposis patients. According to Simbolo et al. [21], multiplex next-generation
DNA sequencing approach has the advantage of analyzing multiple genes in multiple samples simultaneously, making it cost-effective and significantly less time-consuming.

Data from Rohlin et al. [22] confirmed overlapping phenotypes between different herditary CRC syndromes and the importance of using multigene panels. Authors applied a panel including 19 CRC susceptibility genes to 91 individuals of 6 phenotypic subgroups. They revealed a large genetic heterogeneity and overlapping clinical presentation of the different CRC syndromes. They concluded that implementation of multigene-panel-based technology will increase both number of opportunities and challenges in the area of genetic counseling.

\section{Endoscopic Surveillance}

Patients with AFAP have by definition fewer adenomas than FAP patients. Although some reports suggested that majority of adenomas arise from the right colon and that rectum is spared [10,23], a well-designed study by Knudsen et al. [9] found uniform adenoma distribution through colon and rectum in the majority of patients. These to some extent controversial results, however, should not affect clinical practice, since colonoscopy remains the optimal screening tool in AFAP patients.

In classic FAP surveillance, strategies depend on the age distribution of CRC cases in the particular family. Endoscopic screening is lifelong and should be initiated in the early-to-mid teens in individuals with a known mutation $[1,24]$.

In AFAP patients, it is more difficult to design surveillance, since there is limited data that could be used to form guidelines. According to the available guidelines in AFAP, the adenomas and cancer occur 10-20 years later than in typical FAP [1]. A study by Knudsen et al. [9] revealed the risk of CRC development in AFAP is probably lower than in classic FAP. The median age at CRC diagnosis was 55-58 years with the range from 29 to 81 years, that confirmed the findings of several studies, which reported a delay in CRC diagnosis in AFAP of 10-20 years compared with typical FAP [10]. Burt et al. [10] estimated the cumulative risk of CRC in AFAP by age 80 years to be $69 \%$. In another study, the average age of symptomatic presentation was 52 years [25]. In AFAP, colonoscopy may delay the requirement for colectomy, and it is believed that AFAP patients may receive greater benefit from aspirin chemoprophylaxis [26]. 
Table 1. Surveillance strategy according to ACG guidelines [1] for our patient and her siblings

\begin{tabular}{llll}
\hline & Upper GI endoscopy & Colonoscopy & Pouchoscopy \\
\hline $\begin{array}{l}\text { AFAP patient } \\
\begin{array}{l}\text { FAP patient after proctocolectomy with J } \\
\text { pouch (brother and sister) }\end{array}\end{array}$ & Every 4 years* & Every 1-2 years & NA \\
\hline
\end{tabular}

* According to Spigelman stage of duodenal polyposis since the patient was stage 0 , brother and sister were stage I.

NA, non-applicable; FAP, familial adenomatous polyposis; AFAP, attenuated FAP.

In our patient and her siblings, the proposed endocopic surveillance strategy according to ACG guidelines [1] is shown in Table 1.

\section{Indications for Surgical Treatment}

According to the current ACG guidelines, immediate colorectal surgery in FAP, AFAP, and MAP is indicated in cases of documented or suspected cancer or significant symptoms [1]. Surgery might be considered if multiple adenomas larger than $6 \mathrm{~mm}$ are detected, in case of a significant increase in adenoma number between 2 surveillance endoscopies and if high-grade dysplasia is diagnosed in any of resected adenomas. Relative indications for surgery also include the inability to adequately survey the colon because of multiple diminutive polyps [1].

Surgical options include colectomy with ileo-rectal anastomosis (IRA) and ileo-anal pouch anastomosis (IPAA). Colectomy with IRA is a single-stage procedure, while IPAA is a two-stage procedure. IRA is associated with slightly lower morbidity than IPAA surgery. In cases of IRA, there is still a risk of rectal cancer, and proctoscopy should be undertaken yearly [27]. On the other hand, total proctocolectomy and IPAA do not provide a risk-free situation, since adenomas and cancers may occur in the anal transition zone and in the pouch itself; therefore, in these patients, lifelong endoscopic surveillance is also required [28].

Nevertheless, patients with AFAP might never need colectomy and can be efficiently managed with endoscopic polypectomy for decades [10]. In AFAP, IRA is a preferred surgical technique based on data from different studies suggesting rectal sparing and rare cancer occurrence in the remaining rectum. Burt et al. [10] described during the follow-up study only one rectal cancer after IRA. The mean follow-up of this study ranged from 1 to 34 years with a mean follow-up of 7.8 years.

Attenuated FAP

\section{Extracolonic Malignancies}

Extracolonic malignancies include not only gastric and proximal small bowel tumors but also extraintestinal malignancies that can occur in patients with both FAP and AFAP.

Gastric polyps occur in $23-100 \%$ of FAP patients. Majority of lesions are fundic gland polyps, and gastric adenomas are rare [29]. Adenomas in the duodenum are seen in $50 \%$ of FAP patients and lifetime risk for developing duodenal cancer is $3-5 \%$, while the majority of duodenal cancers is diagnosed between 45 and 52 years [30]. Apart from duodenal lesions, small bowel adenomas are localized in the proximal jejunum (50\%) and distal ileum (20\%) [31]. Adenoma and cancer have been also reported in the gallbladder, bile ducts, and pancreas.

Upper GI endoscopy should be part of the diagnostic and surveillance algorithm in both FAP and AFAP patients in the age range 25-30. Upper GI surveillance should include duodenoscopy. If fundic gland polyps are detected, random sampling should be performed. Gastric and duodenal lesions in AFAP patients do not fall into the "attenuated" pattern seen for colorectal polyps and cancer. The expression of gastric and duodenal polyps is not different between AFAP and FAP patients in respect of number, age at emergence, and cancer risk [9]. Surgery is indicated if high-grade dysplasia is detected in adenomas, since low-grade dysplasia is common. Surveillance should be repeated every $0.5-4$ years depending on Spigelman stage of duodenal polyposis [1].

APC gene mutation can also affect the thyroid leading to papillary thyroid cancer and adrenal gland leading to non-functioning adenomas. The presence of osteomas and epidermoid cysts has also been described. Ocular involvement includes congenital hypertrophy of the retinal pigmented epithelium.

Four out of 5 FAP patients have nodular thyroid, while in $12 \%$, thyroid cancer occurs and therefore annual thyroid ultrasound is recommended [32]. 
Hepatoblastoma screening should be done in children whose genetic tests resulted positive for adenomatous polyposis syndrome. It occurs in $1.6 \%$ of FAP patients and is associated with male sex and mutations in the $5^{\prime}$ end of the APC gene. The risk is increased from birth until the age of 15 but this tumor usually occurs in the first 5 years of life. Screening is done every 3-6 months using alpha-fetoprotein and liver ultrasound [33].

Desmoid tumor results from an abnormal growth that arises from the connective tissue. Screening is advised by current guidelines in AFAP and FAP patients. Preoperative abdominal CT scan before colectomy is nevertheless advised [1].

\section{Conclusions}

In AFAP, as opposed to classic FAP, colectomy is not always mandatory and asymptomatic patients can be managed with annual endoscopic surveillance and subsequent polypectomy of detected lesions unless high grade dysplasia is detected. Similar to classic
FAP, the upper GI tract should be carefully surveilled and extracolonic malignanices should not be overlooked.

\section{Ethics Statement} close.

The authors declare that they have no ethical conflicts to dis-

\section{Disclosure Statement}

The authors declare that they have no conflicts of interest to disclose.

\section{Funding Sources}

No funding was obtained for the preparation of data or the manuscript.

\section{Author Contributions}

A.S.M. drafted and wrote the article.

\section{References}

1 Syngal S, Brand RE, Church JM, Giardiello FM, Hampel HL, Burt RW; American College of Gastroenterology. ACG clinical guideline: genetic testing and management of hereditary gastrointestinal cancer syndromes. Am J Gastroenterol. 2015 Feb; 110(2):223-62.

2 van der Luijt RB, Vasen HF, Tops CM, Breukel C, Fodde R, Meera Khan P. APC mutation in the alternatively spliced region of exon 9 associated with late onset familial adenomatous polyposis. Hum Genet. 1995 Dec; 96(6):705-10.

3 Hernegger GS, Moore HG, Guillem JG. Attenuated familial adenomatous polyposis: an evolving and poorly understood entity. Dis Colon Rectum. 2002 Jan;45(1):127-34.

4 Perchiniak EM, Groden J. Mechanisms regulating microtubule binding, DNA replication, and apoptosis are controlled by the intestinal tumor suppressor APC. Curr Colorectal Cancer Rep. 2011 Jun;7(2):145-51.

5 Burt R, Neklason DW. Genetic testing for inherited colon cancer. Gastroenterology. 2005 May;128(6):1696-716.

6 Aretz S, Uhlhaas S, Caspari R, Mangold E, Pagenstecher $\mathrm{C}$, Propping $\mathrm{P}$, et al. Frequency and parental origin of de novo APC mutations in familial adenomatous polyposis. Eur J Hum Genet. 2004 Jan;12(1):52-8.
7 Hes FJ, Nielsen M, Bik EC, Konvalinka D, Wijnen JT, Bakker E, et al. Somatic APC mosaicism: an underestimated cause of polyposis coli. Gut. 2008 Jan;57(1):71-6.

8 Tuohy TM, Burt RW. Somatic mosaicism: a cause for unexplained cases of FAP? Gut. 2008 Jan;57(1):10-2.

9 Knudsen AL, Bisgaard ML, Bülow S. Attenuated familial adenomatous polyposis (AFAP). A review of the literature. Fam Cancer. 2003; 2(1):43-55.

10 Burt RW, Leppert MF, Slattery ML, Samowitz WS, Spirio LN, Kerber RA, et al. Genetic testing and phenotype in a large kindred with attenuated familial adenomatous polyposis. Gastroenterology. 2004 Aug;127(2):444-51.

11 Al-Tassan N, Chmiel NH, Maynard J, Fleming $\mathrm{N}$, Livingston AL, Williams GT, et al. Inherited variants of MYH associated with somatic G:C- $[\{\mathrm{GTT}\}] \mathrm{T}:$ A mutations in colorectal tumors. Nat Genet. 2002 Feb;30(2):227-32.

12 Groves C, Lamlum H, Crabtree M, Williamson J, Taylor C, Bass S, et al. Mutation cluster region, association between germline and somatic mutations and genotype-phenotype correlation in upper gastrointestinal familial adenomatous polyposis. Am J Pathol. 2002 Jun;160(6):2055-61.

13 Nieuwenhuis MH, Vasen HF. Correlations between mutation site in APC and phenotype of familial adenomatous polyposis (FAP): a review of the literature [PubMed: 17064931]. Crit Rev Oncol Hematol. 2007 Feb;61(2): 153-61.

14 Samowitz WS, Thliveris A, Spirio LN, White R. Alternatively spliced adenomatous polyposis coli (APC) gene transcripts that delete exons mutated in attenuated APC. Cancer Res. 1995 Sep;55(17):3732-4.

15 Scott RJ, Froggatt NJ, Trembath RC, Evans DG, Hodgson SV, Maher ER. Familial infiltrative fibromatosis (desmoid tumours) (MIM135290) caused by a recurrent 3' APC gene mutation. Hum Mol Genet. 1996 Dec; 5(12):1921-4.

16 Sieber OM, Lipton L, Crabtree M, Heinimann K, Fidalgo P, Phillips RK, et al. Multiple colorectal adenomas, classic adenomatous polyposis, and germ-line mutations in MYH. N Engl J Med. 2003 Feb;348(9):791-9.

17 Bisgaard ML, Fenger K, Bülow S, Niebuhr E, Mohr J. Familial adenomatous polyposis (FAP): frequency, penetrance, and mutation rate. Hum Mutat. 1994;3(2):121-5.

18 Björk J, Akerbrant H, Iselius L, Alm T, Hultcrantz R. Epidemiology of familial adenomatous polyposis in Sweden: changes over time and differences in phenotype between males and females. Scand J Gastroenterol. 1999 Dec; 34(12):1230-5 
19 Iwama T, Tamura K, Morita T, Hirai T, Hasegawa H, Koizumi K, et al.; Japanese Society for Cancer of the Colon and Rectum. A clinical overview of familial adenomatous polyposis derived from the database of the Polyposis Registry of Japan. Int J Clin Oncol. 2004 Aug;9(4):308-16.

20 Groen EJ, Roos A, Muntinghe FL, Enting RH, de Vries J, Kleibeuker JH, et al. Extra-intestinal manifestations of familial adenomatous polyposis. Ann Surg Oncol. 2008 Sep;15(9):2439-50.

21 Simbolo M, Mafficini A, Agostini M, Pedrazzani C, Bedin C, Urso ED, et al. Next-generation sequencing for genetic testing of familial colorectal cancer syndromes. Hered Cancer Clin Pract. 2015 Aug;13(1):18.

22 Rohlin A, Rambech E, Kvist A, Törngren T, Eiengård F, Lundstam U, et al. Expanding the genotype-phenotype spectrum in hereditary colorectal cancer by gene panel testing. Fam Cancer. 2017 Apr;16(2):195-203.

23 Scott RJ, Meldrum C, Crooks R, Spigelman AD, Kirk J, Tucker K, et al.; Hunter Family Cancer Service. Familial adenomatous polyposis: more evidence for disease diversity and genetic heterogeneity. Gut. 2001 Apr;48(4):508-14.
24 Vasen HF, Möslein G, Alonso A, Aretz S, Bernstein I, Bertario L, et al. Guidelines for the clinical management of familial adenomatous polyposis (FAP). Gut. 2008 May;57(5):704-13.

25 Friedl W, Caspari R, Sengteller M, Uhlhaas S, Lamberti C, Jungck M, et al. Can APC mutation analysis contribute to therapeutic decisions in familial adenomatous polyposis? Experience from 680 FAP families. Gut. 2001 Apr;48(4):515-21.

26 Burn J, Bishop DT, Chapman PD, Elliott F, Bertario L, Dunlop MG, et al.; International CAPP consortium. A randomized placebocontrolled prevention trial of aspirin and/or resistant starch in young people with familial adenomatous polyposis. Cancer Prev Res (Phila). 2011 May;4(5):655-65.

27 Nieuwenhuis MH, Bülow S, Björk J, Järvinen HJ, Bülow C, Bisgaard ML, et al. Genotype predicting phenotype in familial adenomatous polyposis: a practical application to the choice of surgery. Dis Colon Rectum. 2009 Jul;52(7):1259-63.

28 Kartheuser A, Stangherlin P, Brandt D, Remue C, Sempoux C. Restorative proctocolectomy and ileal pouch-anal anastomo sis for familial adenomatous polypo sis revisited. Fam Cancer. 2006;5(3):24160.
29 Burt RW. Gastric fundic gland polyps. Gastroenterology. 2003 Nov; 125(5):1462-9.

30 Latchford AR, Neale KF, Spigelman AD, Phillips RK, Clark SK. Features of duodenal cancer in patients with familial adenomatous polyposis. Clin Gastroenterol Hepatol. 2009 Jun; 7(6):659-63.

31 Alderlieste YA, Rauws EA, Mathus-Vliegen EM, Fockens P, Dekker E. Prospective enteroscopic evaluation of jejunal polyposis in patients with familial adenomatous polyposis and advanced duodenal polyposis. Fam Cancer. 2013 Mar; 12(1):516.

32 Herraiz M, Barbesino G, Faquin W, ChanSmutko G, Patel D, Shannon KM, et al. Prevalence of thyroid cancer in familial adenomatous polyposis syndrome and the role of screening ultrasound examinations. Clin Gastroenterol Hepatol. 2007 Mar;5(3):36773.

33 Giardiello FM, Petersen GM, Brensinger JD, Luce MC, Cayouette MC, Bacon J, et al. Hepatoblastoma and APC gene mutation in familial adenomatous polyposis. Gut. 1996 Dec; 39(6):867-9. 